\title{
Anaerobic Digestion Foaming Causes - A review
}

\author{
Nafsika Ganidi ${ }^{2}$, Sean Tyrrel ${ }^{1}$, Elise Cartmell ${ }^{2}$ \\ Centre for Water Science, School of Applied Sciences, Cranfield University, \\ Cranfield, Beds, MK43 0AL, UK
}

ABSTRACT: Anaerobic digestion foaming has been encountered in several sewage treatment plants in the UK. Foaming has raised major concerns for the water companies due to significant impacts on process efficiency and operational costs. Several foaming causes have been identified over the past few years by researchers. However, the supporting experimental information is limited and in some cases absent. The present report aims to provide a detailed review of the current anaerobic digestion foaming problem and to identify gaps in knowledge regarding the theory of foam formation in anaerobic digesters.

KEYWORDS: Anaerobic digestion, foaming, sludge.

\footnotetext{
${ }^{1}$ Corresponding author: Sean Tyrrel, Centre for Water Science, Bld 40, Cranfield University, Cranfield, Beds, MK43 OAL, UK, Phone no: +44 (0)1234 750111, Fax: +44 (0)1234 751671, Email: s.tyrrel@cranfield.ac.uk

${ }^{2}$ Co-authors address: Centre for Water Science, Cranfield University, Cranfield, Beds, MK43 $O A L, U K$
} 


\section{Introduction}

Anaerobic digestion $(\mathrm{AD})$ foaming has been recorded in many sewage treatment works (STWs) for over a decade with severe impacts on the overall digestion process (Barjenbruchh et al. 2000, Barber 2005). Oerther et al. (2001) have characterized microbial foams generated on the surface of activated sludge as a viscous, deep brown- colored layer. Varley et al. (2004) have also characterized foam of a culture medium as 'a gas-liquid dispersion with gas content of more than $95 \%$, produced due to intense agitation, aeration and the presence of surfactants'. Based on the above statements, foams created in anaerobic digesters could be characterized as an accumulation of gas bubbles surrounded by a liquid film on the surface of sludge.

Foaming results in inefficient gas recovery from the digesters creating additional costs for electricity production. Foaming can also result in an inverse solids profile having higher solids concentrations at the top of a digester, creation of dead zones and reduction of the active volume of the digester hence resulting in sludge, which has not received the same degree of stabilization. Other problems caused by foaming can include blockages of gas mixing devices, foam binding of sludge recirculation pumps, fouling of gas collection pipes due to entrapped foam solids, foam penetration between floating covers and digester walls and tipping of floating covers during foam expansion and collapse. The economic issues that arise from energy loss, manpower overtime 
and cleaning costs are of major concern to the wastewater industries (Pagilla et al. 1997, Westlund et al. 1998, Barjenbruch et al. 2000, Barber 2005). Westlund et al. (1998) reported that a STW in Sweden suffered in 1996 from 40\% biogas loss after a 10-week foaming incident. The total cost of suppressing foam, which included the additional oil consumption for energy production and the usage of polymer for improved dewatering, reached $\$ 150,000$ US Dollars. However, this is the only reference found in the literature on costs arising from foaming events in anaerobic digestion.

A number of researchers have investigated the foaming problem in $A D$ in order to identify the foaming causes. Initially, Ross and Ellis (1992) suggested that AD foaming was related to organic overloading and the accumulation of acetic acid in digesters. According to a study conducted by Pagilla et al. (1997), Gordonia filamentous bacteria were identified as the cause of foaming in two full scale anaerobic digesters at the Sacramento Regional STWs. A following study by Westlund et al. (1998) reported that Microthrix filamentous bacteria were the foaming cause at a full scale anaerobic digester in Stockholm. Recent suggestions, according to Barber (2005) and Barjenbruch et al. (2000), have identified parameters, such as inadequate mixing, temperature fluctuations, shock loads, extracellular polymeric substances (EPS) and hydrophobic substances as foaming causes. However, the above reports do not represent a systematic investigation of the foaming problem as the information provided is either site specific or lacks experimental evidence. 
The present report aims to review the current knowledge on foaming causes in mesophilic $A D$ and investigate the foaming mechanisms during $A D$. Wider knowledge of a well-studied foaming problem in biological processes, activated sludge (AS) foaming, is addressed in the following paragraphs in order to promote a better understanding regarding the mechanisms of foam formation and stabilization in biological processes where continuous degradation, solid contents and the microbial population have an impact on foam initiation and stabilization and to provide useful information on understanding the mechanisms of foaming in AD. Comparison with the AS process was completed to: a) aim to potentially identify a relationship between $A S$ foaming and $A D$ foaming; and b) study a more extensive literature on foam initiation and foaming mechanisms than available for AD. Foaming in other biological processes such as aerobic digestion (Staton et al. 2001) and up flow anaerobic sludge blankets (UASB) (Kalyuzhnyi et al. 1998) was not studied as there is little information in the literature on foaming in such processes.

\section{Activated sludge foaming - The best studied example}

The activated sludge (AS) process is extensively used in wastewater treatment and involves the degradation of organic matter by microorganisms under diffused or mechanical aeration (Metcalf and Eddy 2003). Foaming is a widespread problem in AS plants and there is extensive information in the literature on the foaming causes and control. This section aims at reviewing in 
brief the well-studied foaming problem of AS plants in order to gain knowledge from the literature on wastewater foams and potentially recognize a relationship between AS foaming and AD foaming.

Foaming in activated sludge plants is described as floating biomass and has been attributed by many researchers to the combination of the presence of surfactants (detergents), biosurfactants (substances produced during the metabolic activity of microorganisms) and the presence of two groups of filamentous bacteria, Gordonia spp. (formerly known as Nocardia sp.) and Microthrix parvicella. The filamentous microorganisms are generally bacteria, fungi and algae whose cells do not become detached from one another after cell division and therefore tend to grow in the form of 'filaments'. Gordonia spp. comprise of filamentous microorganisms, known as Actinomycetes, which are extremely hydrophobic due to the presence of mycolic acids on their cell walls (Stainsby et al. 2002, de los Reyes and Raskin 2002). Microthrix parvicella is also hydrophobic and utilizes long chain fatty acids as carbon source. It can store excess long chain fatty acids in large globules and has an advantage over other bacteria for water-insoluble fats and lipids due to its hydrophobicity (Mamais et al. 1998). The mycolic acids in their cell walls make them sufficiently hydrophobic and along with the morphological characteristics of filamentous bacteria they become attached on the gas bubbles present in activated sludge and rise to the surface of the liquid increasing the surface activity and promoting stable foams (Mamais et al. 1998, Eikelboom 2000, Oerther et al. 2001, de los 
Reyes and Raskin 2002, Davenport and Curtis 2002, Torregrossa et al. 2005, Carr et al. 2006, Hug 2006, Kragelund et al. 2007).

De los Reyes and Raskin (2002) carried out batch tests involving the addition of Gordonia amarae cells to AS and found that the threshold of Gordonia levels for foam formation and foam stability were approximately $2 \times 10^{8} \mu \mathrm{m} / \mathrm{ml}$ and $1 \times 10^{9}$ $\mu \mathrm{m} / \mathrm{ml}$ (filament length), respectively. The results were verified by full scale and laboratory scale measurements.

Davenport and Curtis (2002) found that large rod and coccoid mycolata numbers (mycolic-acid containing bacteria) varying from approximately $8 \times 10^{6}$ to $30 \times 10^{6}$ per $\mathrm{ml}$ of AS and accounting for more than $79 \%$ of the mycolata population were highly associated with foaming events at three full-scale AS plants. However, branched filamentous mycolata presence in foaming periods was insignificant, accounting for less than $21 \%$ of the mycolata population in the mixed liquor and foam samples examined. Furthermore, filamentous mycolata did not contribute to any of the significant differences in mycolata concentration observed between foaming and non-foaming periods. These findings indicated that filamentous microorganisms were not the cause of foaming on this occasion.

De los Reyes et al. (2002) reported that large numbers of M. parvicella and even inactive M. parvicella cells were linked with foaming in AS. The length of M. parvicella in the monitored foaming AS plants varied from just above $0 \mu \mathrm{m}$ 
per $\mathrm{ml}$ to $2.6 \times 10^{9} \mu \mathrm{m}$ per $\mathrm{ml}$ of AS. Hwang and Tanaka (1998) also stated that seasonal foaming at an activated sludge plant was attributed to increased levels of M.parvicella with persistent foaming corresponding to filament length between 200 and $500 \mu \mathrm{m}$.

Foaming in AS plants is regarded as a 3-phase system, comprising of gas bubbles, liquid (wastewater) and solid particles (hydrophobic bacteria) (Davenport and Curtis 2002). Hug (2006) stated that the onset of foaming could be due to high surfactants and biosurfactants loads in wastewater, which is then stabilized by the mycolic-acid containing microorganisms. Another study investigated the effect of three strains of the filamentous bacterium Gordonia amarae on foam initiation and stabilization. Pure cultures of the three strains after isolation of the microorganisms from foam or mixed liquor samples from full scale showed that the agent responsible for foam initiation was the biosurfactant produced during the exponential growth phase of the G.amarae strains and not the G.amarae bacteria. It was also found that each strain produced a different biosurfactant or at different quantities as the filtrates of each culture had different foaming behaviour. Although the biosurfactants were not quantified in this study, their concentrations were measured indirectly through surface tension and the foaming potential and surface tension values below $60 \mathrm{mN} . \mathrm{m}^{-1}$ were necessary for foam initiation. The stabilization of foam was attributed to the presence of G.amarae as $\geq 55 \%$ of the strains was partitioned into the foam resulting in reduction of the foam drainage rates. The partitioning of the bacteria in the foam was not associated with the origin of the 
strains (foam or mixed liquor sample) and did not change greatly with the life cycle (Heard et al. 2008).

In conclusion, foaming in AS plants is a well-studied problem by many researchers with significant impacts on the process efficiency. Several studies by various researchers have demonstrated a clear link between the AS foaming and the presence of surfactants, biosurfactants and the mycolic-acid containing

microorganims. Recent studies (Hug 2006, Heard et al. 2008) have showed that initiation of AS foaming is due to surfactants and biosurfactants, although critical concentrations for foam initiation have not been quantified due to the numerous compounds involved and their variability between different sludges. Foam stabilization is mainly due to the filamentous Gordonia and M.parvicella but there is evidence suggesting that non filamentous mycolic-acid containing microorganisms, of which specific species have not yet been identified, also act as stabilizing agents. Additional information on the exact mechanisms of foam generation and stabilization in AS plants has not been provided potentially due to the complexity of the process (degradation pathways and numerous surface active compounds present in wastewater).

\section{Anaerobic digestion foaming}

Current knowledge of the AS foaming problem has provided fundamental understanding of the mechanisms of wastewater foaming. In order to identify 
similarities regarding the mechanisms of foam formation and stabilization in $A D$ and potentially the relationship between $A S$ foaming and $A D$ foaming, the following paragraphs evaluate the effect on foaming in relation to chemical (surface active agents) and microbiological components.

\subsection{Surface active agents}

The term 'surface active agents' refers to substances that are either surfactants or bio-surfactants. The surfactants include oil, grease, volatile fatty acids, detergents, proteins and particulate matter (Vardar-Sukan 1998, Westlund et al. 1998, Barber 2005). However, the term 'particulate matter' as found in the literature is not clearly stated and can lead to confusion and misinterpretations. The particulate matter involves potentially the inorganic components of sludge, often referred to as grit, such as metals, sand and generally indigestible material that accumulates at the bottom of digesters. The term biosurfactants refers to substances produced during the metabolic activity of microorganisms found in sludge, such as hydroxylated and cross-linked fatty acids, glycolipids, proteins, lipoproteins, phospholipids and polysaccharide-lipid complexes (Kosaric 1992, Ron and Rosenberg 2002, Nitschke and Pastore 2006).

Surface active agents have both hydrophilic and hydrophobic properties. The hydrophobic ends of surface active agents tend to move towards the air phase, being forced out of the solution due to their hydrophobicity. The hydrophilic ends, on the contrary, tend to move towards the liquid phase. Surface active 
agents have an impact on the surface tension of a solution, where surface tension is defined as 'a property of liquids arising from unbalanced molecular cohesive forces at or near the surface, as a result of which the surface tends to contract and exhibit properties resembling those of a stretched elastic membrane' (Dictionary of the English Language 2000). The examination of surface tension against the concentration of a surface active compound identifies its critical micelle concentration $(\mathrm{cmc})$. That is the concentration of the compound at which the aggregation of molecules into clusters (micelles) starts by orientation of the hydrophobic ends of the molecules towards the centre and the hydrophilic ends towards the solution. At concentrations lower than the $\mathrm{cmc}$, the molecules of the compound exist as monomers, whereas at concentrations higher than the cmc as micelles (Elmitwalli et al. 2001, Ying 2006). According to Schramm (2000), the effect of the compound is greatest at concentrations higher than the $\mathrm{cmc}$ where a significant number of micelles are present. Simply, the $\mathrm{cmc}$ of a surface active compound determines the concentration beyond which surface activity increases and foaming would appear if air bubbles were introduced into solution. The surface tension of pure water is approximately 72 $\mathrm{mN} \cdot \mathrm{m}^{-1}$ at $20^{\circ} \mathrm{C}$ (Vardar-Sukan 1998) and there is extensive information in the literature referring to the effect of individual compounds on surface tension and their critical micelle concentrations. Clarkson et al. (1999), for instance, reports that the apparent $\mathrm{cmc}$ of the protein bovine serum albumin (BSA) is $0.03 \mathrm{mg} \cdot \mathrm{ml}^{-}$ 1. Nino and Patino (1998) identify the cmc of Tween 20 (polyoxyethylene sorbitan monolaurate) at $1.69 \mathrm{M} \times 10^{5}$. Garcia et al. (2006) identify the $\mathrm{cmc}$ of linear alkylbenzene sulphonates (LAS) as decreasing with increasing alkyl chain 
length of the LAS homologue $\left(1.5 \mathrm{M} * 10^{-3}-2.0 \mathrm{M} * 10^{-5}\right)$. Further examples of the effect of specific compounds on surface tension are given in the following paragraphs.

All the above mentioned surface active agents, i.e. oil, grease, volatile fatty acids (VFAs), detergents, proteins and products from the metabolic activity of microorganisms are largely present in anaerobic digesters (Gerardi 2003). However, it is known that these substances break down in a digester into smaller and simpler compounds. A better look into the degradation pathways and the by-products of these compounds during anaerobic digestion could provide further understanding of the impact of surface active agents on foaming during $A D$.

Proteins are complex compounds with high molecular weights, that can vary from $14.6 \mathrm{kD}$ to $250 \mathrm{kD}$ based on a report by Clarkson et al. (1999) and they do not dissolve or settle in wastewater. In sludge, they are found in solution as soluble microbial products but also attached to the solid particles as extracellular polymeric substances (EPS). Due to the size of proteins, microorganisms produce exoenzymes (proteases or peptidases) to break down the proteins into smaller compounds (amino acids) and subsequently absorb them into their cells to utilize the carbon source. Amino acids are converted to organic acids once inside the cells, which are then released along with ammonia into the bulk phase. Organic acids are the substrate for methane 
forming bacteria and as digestion proceeds $\mathrm{CH}_{4}$ and $\mathrm{CO}_{2}$ are produced (Gerardi 2003).

Proteins have been recognized as foam forming agents by many researchers and the cmcs' of many proteins are available in the literature (Khan and Forster 1990, Clarkson et al. 1999, Glinski et al. 2000, Rouimi et al. 2005, Foegeding et al. 2006, Glaser et al. 2007). Khan and Forster (1990) conducted aeration tests with a non-foaming AS to determine the impact of a protein in the foaming potential of AS. The protein used in the experiments was bovine serum albumen (BSA) at concentration of $2 \mathrm{~g} \cdot \mathrm{I}^{-1}$. Khan and Forster (1990) reported that BSA induced foam in AS under aeration, however, with low stability. Vardar-Sukan (1998) stated that proteins exhibit their lowest solubility and highest foaming potential at their isoelectric point, which is highly dependant on the $\mathrm{pH}$ of the medium. So far no information is available in the literature on how different proteins affect the foaming potential in anaerobic digesters and what concentrations are critical above which foaming is induced. There is indication from the experiments conducted by Khan and Foster (1990) that BSA would induce foaming in digester feed sludge under aeration. However, proteins are broken down to amino acids in anaerobic digesters by exoenzymes and their impact on the foaming potential is reduced. Gonzales et al. (2003) found that the protein content in $\mathrm{AD}$ was less biodegradable than fiber and lipids and that there was a final equilibrium concentration value of $8.41 \mathrm{mg} \cdot \mathrm{g}^{-1}$ for each nonfoaming sludge that was independent of the initial protein concentration. The maximum initial protein concentration tested in this study was $44.8 \%$ of dry 
matter of sludge. Accumulation of proteins at the air/liquid interface could be facilitated during AD due to their surface active properties, which could then lead to enhanced foaming potential. On the other hand, the interaction of proteins with other proteins, solids and other compounds in solution could also affect the behavior of proteins, such as the electrostatic interactions reported by Glaser et al. (2007) between BSA and protamine resulting in a molecular double layer entrapping liquid, which reduced drainage thus increasing foam stability. Other types of interaction include the affinity of proteins to fat, as described by Eisner et al. (2007), in the protein - fat mixture containing $9.75 \%$ molten butter (82\% fat content), $11.3 \%$ spray dried skim milk powder (low heat), 12\% sugar, $4 \%$ glucose syrup solids, $0.1 \%$ locust bean gum and $0.1 \%$ guar gum by weight, which resulted in bridging between adjacent foam bubbles and between bubbles and the bulk solution resulting in reduced foam drainage and hence the creation of more stable foams. However, it was demonstrated in the same report that the presence of nonionic emulsions of monolaurate $(0.9 \mu \mathrm{M})$, monooleate $(0.7 \mu \mathrm{M})$ and trioleate of sorbitan $(0.3 \mu \mathrm{M})$ in the protein - fat matrix reduced the foaming potential and stability. Investigation of the effect of proteins, the proteins by-products, the interactions between compounds and potentially the production of exoenzymes that could affect the foaming potential in anaerobic digesters is complex and can vary between different sludges. So far, it is unknown whether sludge containing very surface active proteins, such as lysozome of which $0.001 \mathrm{mM}$ reduced the surface tension of aqueous solution to below $58 \mathrm{mN} \cdot \mathrm{m}^{-1}$, as it was demonstrated by Clarkson et al. (1999), would be more likely to foam during AD compared to sludge containing less 
surface active proteins and hence provide an indication of sludge streams more prone to foaming or if the presence of proteins independent of their surface activity is adequate to contribute to / result in foaming.

Volatile acids are a group of organic acids, often described as volatile fatty acids (VFAs). They can vary in length but generally are low molecular weight (MW) compounds, soluble in water and sludge. Seven of the commonest fatty acids found in anaerobic digesters are formic acid $(\mathrm{HCOOH}, \mathrm{MW}: 46.03)$, acetic acid $\left(\mathrm{CH}_{3} \mathrm{COOH}, \mathrm{MW}: 60.05\right)$, propionic acid $\left(\mathrm{CH}_{3} \mathrm{CH}_{2} \mathrm{COOH}, \mathrm{MW}: 74.08\right)$, butyric acid $\left(\mathrm{CH}_{3}\left(\mathrm{CH}_{2}\right)_{2} \mathrm{COOH}, \mathrm{MW}: 88.10\right)$, valeric acid $\left(\mathrm{CH}_{3}\left(\mathrm{CH}_{2}\right)_{3} \mathrm{COOH}\right.$, $\mathrm{MW}: 102.13)$, iso-valeric acid $\left(\left(\mathrm{CH}_{3}\right)_{2} \mathrm{CHCH}_{2} \mathrm{COOH}, \mathrm{MW}: 102.13\right)$ and caproic acid $\left(\mathrm{CH}_{3}\left(\mathrm{CH}_{2}\right)_{4} \mathrm{COOH}, \mathrm{MW}: 116.15\right)$. The ranges of the above acids in digesters usually vary between 50 and $300 \mathrm{mg}^{-1}{ }^{-1}$ as total VFAs concentration. Acetic acid is the predominant acid and accounts for approximately $85 \%$ of the volatile acids content in an anaerobic digester (Metcalf and Eddy 2003, Gerardi 2003). Accumulation of acetic acid has been identified in the literature as a foaming cause by many researchers (Pagilla et al. 1997, Westlund et al. 1998, Barjenbrugh et al. 2000). This is understandable as methanogenic bacteria are the only bacteria that utilize acetic acid and they are characterized by slow growth rates (they can reproduce within 3 days at $35^{\circ} \mathrm{C}$ according to Handbooks of UK Wastewater Practise (1996) and Gerardi (2003)), which indicates that fluctuations resulting in excess acetic acid concentrations in an anaerobic digester would result in degradation of only the maximum uptake of acetic acid by the methanogens with the remaining acetic acid lowering the $\mathrm{pH}$ of the 
digester and inhibiting the digestion process. However, there is no experimental or quantitative evidence in the literature to support the above interpretation that accumulation of acetic acid leads to foaming in $A D$ and the critical concentration of acetic acid in sludge beyond which digestion inhibition and potentially foaming occurs is unknown.

Lipids are extremely hydrophobic organic molecules that do not dissolve in water. Due to their hydrophobicity, lipids are attached to the solid particles in sludge. The most common lipids in municipal and industrial wastewater, and subsequently in sludge are fats and oils. Fats and oils that enter a digester, although surface active agents as previously stated, are hydrolyzed to simpler compounds (glycerol and fatty acids) to give ultimately organic acids (Gerardi 2003). Fats and oils are mainly present in primary sludge at concentrations between 6.4 to $14.8 \%$ of dry matter but can also be detected in digesters and SAS in smaller concentrations (digesters: $2.4-9.0 \%$, SAS: $0.8-2.52 \%$ of dry matter) (Gonzales et al. 2003). Gonzales et al. (2003) found that lipids were utilized by microorganisms in AD faster than proteins and similarly, there was a final equilibrium concentration value of $1.07 \mathrm{mg} \cdot \mathrm{g}^{-1}$ for each sludge tested that was independent of the initial lipid concentration. Given the hydrophobicity of lipids but also their degradability during $A D$, it is not clear whether lipids would potentially accumulate on the surface of the bulk phase in an anaerobic digester, losing contact with the majority of bacteria found in the bulk phase and hence leading to partial degradation of fats and oils and increased surface activity. The biogas bubbles could become entrapped due to the surface active 
properties of the lipids and potentially induce foaming. However, additional experimental data demonstrating a clear contribution of lipids to the sludge's foaming potential during AD were not found in the literature. There is indication that lipids contribution to foaming in $A D$ is potentially smaller than the proteins contribution due to the low degradability of proteins and accumulation of lipids at the air/liquid interface resulting in increases surface activity could be eliminated by maintaining a well mixed homogenous digester.

Detergents are another group of compounds recognized as surface active agents. Detergents present in wastewater derive from industrial effluents, such as breweries, dairies, paper and textile industries but also from municipal wastewater. Industrial effluents can significantly increase the concentrations of detergents that enter a STWs to such an extent that they can inhibit biological treatment processes (Leitao et al. 2006). The most important group of detergents is the linear alkylbenzene sulphonates (LAS). LAS are characterized as anionic surfactants and are the most frequently used world wide in both domestic and industrial applications. It has been found by Jensen (1999) that a large amount of LAS is adsorbed onto the particles and organic matter of sludge and is removed from the wastewater via primary sludge. Due to the high degradability of LAS under aerobic conditions, primary sludge is the only stream that will contain substantial detergent concentrations. However, the amount of LAS in the final sludge (mixture of primary and secondary sludge) is highly dependant on the site processes. (Table 1 shows the concentrations of LAS found in sludge derived from different STWs) 
Prats et al. (1997) examined the removal of anionic (LAS) and nonionic detergents in wastewater treatment plants. The findings from this study revealed that during sludge settling and subsequently anaerobic digestion of sludge, the degradation of the nonionic detergents was $27 \%$ and only $7 \%$ for LAS. Jensen's (1999) finding that detergents are adsorbed onto the solids and organic matter is also supported by Prats et al. (1997) who showed that most of the detergent was removed by attachment to the suspended solids. According to Petrovic and Barcelo (2004), LAS concentrations in sewage sludge can range from $100 \mathrm{mg} \mathrm{kg}^{-1}$ to $30 \mathrm{~g} \mathrm{~kg}^{-1}$ and are highly dependant on the site processes. In the same report, it is also stated that LAS concentrations in sludges obtained from three STWs in Spain were in the range of 8.4-14.0 $\mathrm{mg} . \mathrm{g}^{-}$ ${ }^{1}$ (average $12.6 \mathrm{mg} / \mathrm{g}$ ) and $12.1-18.8 \mathrm{mg}^{-\mathrm{g}^{-1}}$ (average $15.8 \mathrm{mg} \cdot \mathrm{g}^{-1}$ ) before and after digestion, respectively. However, it is not stated in the report whether foaming was recorded in the digesters of the STWs in Spain. Along with LAS, Petrovic and Barcelo (2004) examined other groups of detergents such as NPEOs $_{n}$ (nonylphenol ethoxylates, $\left.n: 1-15\right)$ and AEOs (alcohol ethoxylates) and found that significant amounts of short-chain NPEOs and AEOs are also retained during anaerobic digestion. Typically, they mentioned that NPEOs concentrations range from a few $\mathrm{mg} / \mathrm{kg}$ to over $500 \mathrm{mg} / \mathrm{kg}$, and for AEOs, which are the second most widely used surfactants worldwide, maximum concentrations can reach $300 \mathrm{mg} / \mathrm{kg}$ and removal efficiencies range from $33 \%$ to $86 \%$ during $A D$. The low removal of detergents during $A D$, especially for the anionic detergents, along with their properties as surface active agents results 
in increased surface activity in sludge that could potentially contribute to foaming events in $A D$.

The information found in the literature for biosurfactants in sewage sludge, such as glycolipids, lipoproteins, phospholipids, polysaccharide-lipid complexes and their association to foaming is limited, potentially due to the numerous and complex compounds present and the variability of these compounds between different sludges. Indirect biosurfactants measurements have been conducted by researchers in wastewater, soil or other bacterial culture media samples (Pirog et al. 2003, Verma et al. 2006, Nitschke and Pastore 2006). Nitschke and Pastore (2006) conducted surface tension measurements in a wastewater based culture medium of a bacterial species to monitor the biosurfactants production. The biosurfactant, which was identified as a lipopeptide, reduced the surface tension of the culture medium to $26 \mathrm{mN} \cdot \mathrm{m}^{-1}$ at concentration of $3 \mathrm{~g} \cdot \mathrm{I}^{-1}$ while its cmc was $33 \mathrm{mg}^{-1} \mathrm{I}^{-1}$. The large and diverse microbial population in anaerobic digesters would suggest that the production of biosurfactants in digesters is significant. However, biosurfactants are present in AD under nonfoaming conditions. It is not clear whether an upset in the metabolic activity of microorganisms in $A D$ is necessary to result in higher production of biosurfactants that would facilitate foaming. Therefore, biosurfactants might not be a direct $A D$ foaming cause but an effect of an underlying cause that triggers the production of biosurfactants. Additionally, the likelihood of these compounds to induce foaming in a digester would probably depend on the type of biosurfactants present and their concentrations. No conclusion can be made at 
this stage for the contribution of biosurfactants in AD foaming due to lack of experimental evidence.

In summary, a large number of compounds commonly found in anaerobic digesters are surface active. The impact of surface active agents on AD foaming depends on the properties of each compound. The literature has suggested that the effect of proteins in a digester is greater as they are less biodegradable than lipids and fiber. Accumulation of acetic acid has been suggested as a foaming cause with no supporting experimental evidence and anionic detergents presence in $A D$ is significant due to their low degradability under anaerobic conditions. During digestion, however, two major factors need to be taken into consideration a) interactions between compounds and between the compounds and solids in sludge could enhance or reduce the foaming potential, as discussed in previous paragraphs and b) the surface active agents are broken down to simpler compounds (organic acids) during AD and are utilized by the bacteria and therefore their impact on the foaming potential is unclear. Unstable digestion, however, such as accumulation of acetic acid and its partial utilization by the methanogens, as explained earlier, or accumulation of proteins and detergents due to their low degradability during $A D$, could initiate or contribute to foaming. Therefore, it is necessary to determine quantitatively or qualitatively, i.e. through surface tension measurements (Pirog et al. 2003, Verma et al. 2006, Nitschke and Pastore 2006) or aeration tests (Khan and Forster 1990), as previously done by other researchers, the critical 
concentrations of surface active agents necessary to induce and / or stabilize foaming during $A D$.

\subsection{Filamentous microorganisms}

A number of reports in the literature have identified Gordonia species and Microthrix parvicella as the cause of foaming in AD (Pagilla et al. 1997, Westlund et al. 1998, Moen 2003, Barber 2005). However, there is no differentiation between foam initiation causes and foam stabilization causes when referring to the above filamentous species. Gordonia species and Microthrix parvicella are present in anaerobic digesters via surplus activated sludge (SAS). They can be present in the liquid phase but also bound to the flocs. Although, they are primarily aerobic organisms, literature has shown that they can survive under anaerobic conditions, as discussed in following paragraphs. Their hydrophobic properties tend to drive the filamentous microorganisms towards the air/liquid interface as the microorganisms become attached to the biogas bubbles. The accumulation of filamentous microorganisms on the air/liquid interface of anaerobic digesters along with the potential of biosurfactants production, results in lower surface tension of sludge and enhanced foaming potential (Eikelboom 2000, Barber 2005).

Hernandez and Jenkins (1994) studied the fate of Gordonia during mesophilic anaerobic digestion of sludge. Severe foaming was induced at laboratory scale batch digestion experiments at concentrations of Gordonia spp. between 0.05- 
$0.1 \mathrm{~g}$ Gordonia / $\mathrm{g}$ total solids. That concentration matched the range of $\mathrm{g}$ Gordonia per $\mathrm{g}$ total solids observed at full scale digesters that experienced foaming. Hernandez and Jenkins (1994) reported that, although Gordonia spp. are known to be obligate aerobes, they survived under anaerobic conditions with only $37 \%$ filament reduction at a 14-day SRT and $60 \%$ of these filaments capable of respiration after 14 days. Another interesting finding was that viability of Gordonia spp. decayed more slowly in single-phase digestion than in twophase with a first order rate coefficient for single-phase digestion of 0.02 / day. Mamais et al. (1998) supported these findings by stating that Microthrix is capable of surviving under anoxic and / or anaerobic conditions.

Westlund et al. (1998) monitored the presence and abundance of filaments during an anaerobic digester foaming incident at the full scale. Filaments were identified microscopically in the foam and bulk phase of sludge. The dominant species of filaments was recognized as Microthrix parvicella. Table 2 lists the characteristics of the sludge and foam samples obtained from the digester during foaming and compares them with sludge characteristics obtained from the same digester when foaming was not recorded. Westlund et al. (1998) carried out laboratory tests with samples obtained from the foam phase of the digester. The foam samples were collected in a glass vessel and the potential to force the foam sample to foam again was tested by shaking the glass vessel. The foam sample collapsed, when shaking the glass vessel, to produce sludge and it was not possible to foam again. Microthrix filaments were found attached to the gas bubbles in the foam samples after microscopic examination. 
According to Westlund et al. (1998) it was concluded that Microthrix was bound to the gas bubbles during digestion producing the foam. The binding between the gas bubbles and the filaments was strong in order not to release the gas during digestion and only by shaking the foam the gas bubbles could be released and foam could be destroyed.

Pagilla et al. (1997) also monitored the levels of filaments along with other operational data of two full scale anaerobic digesters for a period of 10 months. Foaming was recorded in the digesters during the period of sampling. The two digesters were operated under the same conditions but one of them was mechanically mixed and the other gas mixed. The presence of excessive levels of Gordonia in the feed sludge (up to $10^{7}$ numbers per gram VSS) coincided with an increase of the foam layer with a more pronounced effect in the gas mixed digester.

Soddell and Seviour (1995) determined the ability of mainly Nocardia and other filament species to grow in a wide temperature range. The filaments were isolated from foaming activated sludge and cultivated in laboratory conditions at different temperatures. The majority of the filaments species examined could grow in cultures in the mesophilic range of $30-35^{\circ} \mathrm{C}$, indicating that the temperature in mesophilic AD would have no adverse impacts in filaments growth. A major factor that needs to be taken into consideration is that in cases of foaming in mesophilic $A D$, the temperature in the foam matrix is lower than 
the temperature in the bulk phase, which, according to the study of Soddell and Seviour (1995), favors the growth of more species in the foam matrix.

According to the information provided above, Gordonia and Microthrix are the species that have been found to induce foaming in AD. The same species were found responsible for AS foaming. The findings of Hernandez and Jenkins (1994) clearly demonstrated at both full and laboratory scale that concentrations between $0.05-0.1 \mathrm{~g}$ Gordonia / $\mathrm{g}$ total solids resulted in severe foaming during AD. However, two different species of filaments were identified as the causative foaming agent at full scale digesters in the reports by Pagilla et al. (1997) and Westlund et al. (1998). Earlier in this section, knowledge on AS foaming was reviewed in order to identify potential similarities between AS and AD foaming. Recent publications on AS foaming have shown that it is the biosurfactants production by Gordonia spp and Microthrix and potentially other mycolata that initiate foaming but the bacteria that stabilize it. So far, only the presence and abundance of these species has been investigated in relation to AD foaming and not the biosurfactants production. There is evidence that the reduction in filament numbers in $A D$ is small and hence the production of biosurfactants by these species could still occur during AD indicating the same foaming mechanisms in both AS and AD. Investigation of the impact of other filament species with similar morphological characteristics (i.e. hydrophobicity due to mycolic acids) on foaming in AD would provide useful information about the extent filaments are responsible for foaming. 


\subsection{Temperature}

Dohanyos et al. (2004) stated that thermophilic digestion is more resistant to foam generation than mesophilic digestion. This could be attributed to the effect of higher temperatures on lowering the surface tension and viscosity of sludge and hence increasing foam drainage (Hayta et al. 2001, Barber 2005).

Thermophilic digestion, therefore, could be effective in foam minimization and/or destruction where foam is constantly present.

Another factor that needs to be taken into consideration when investigating the relationship between temperature and foaming, are temperature fluctuations due to technical site failures. The only experimental evidence on the effect of temperature fluctuations during anaerobic digestion is provided by Chae et al. (2008), who studied the AD of swine manure and showed that a temperature decrease and subsequent increase from $35^{\circ} \mathrm{C}$ to $30^{\circ} \mathrm{C}$ to $32^{\circ} \mathrm{C}$ affected only the biogas yield. No reference to foaming was found in the report during the digestion period. According to Chae et al. (2008), the temperature was lowered from $35^{\circ} \mathrm{C}$ to $30^{\circ} \mathrm{C}$ during digestion and maintained for 170 hours. However, the biogas production rate resumed to the values of the control after 40 hours of the change. Similarly, the temperature change from $30^{\circ} \mathrm{C}$ to $32^{\circ} \mathrm{C}$ and subsequent digestion period of approximately 200 hours showed a temporary decrease in biogas yield, which again matched the control values after about 40 hours of the change. The effect of temperature fluctuations greater than the ones studied by Chae et al. (2008) to the metabolic activity of microorganisms in AD, which could lead to accumulation of surface active agents due to the microbial upset 
and poor digestion and potentially foaming has not been reported in the literature.

\subsection{Organic loading}

A number of researchers have stated that organic overloading of digesters can be a cause of foaming (Pagilla et al. 1997, Barjenbrugh et al. 2000, Brown 2002, Moen 2003, Barber 2005). This could be due to the excess of compounds not being fully degraded by the bacteria within digesters, leading potentially to accumulation of hydrophobic or surface active by-products that would promote foaming. According to the literature, the typical ranges of organic (volatile solids, VS) loading rates for conventional mesophilic anaerobic digestion of municipal sludge, as shown in Table 3, can vary greatly from values as low as $0.7 \mathrm{~kg}$ VS.m $\mathrm{m}^{-3} \mathrm{~d}^{-1}$ up to $7.2 \mathrm{~kg}$ VS.m $\mathrm{m}^{-3} \mathrm{~d}^{-1}$. Brown (2002) suggests that operating digesters at organic loading rates higher than $4.5 \mathrm{~kg} \mathrm{VS} \cdot \mathrm{m}^{-3} \mathrm{~d}^{-1}$, even though they are still within the suggested operational range according to Table 3 , usually results in foaming. None of the other reports found in the literature provide quantitative information to support the above statements. Hence, although organic loading is put forward as a foaming cause by many researchers, there is still lack of fundamental information to demonstrate a clear correlation between foaming and organic loading of digesters. Given that sludge characteristics can be different between digesters, it could be possible that each digester has a critical organic loading threshold above which foaming appears. 


\subsection{Mixing and digester shape}

Mixing aims to achieve optimum process performance by keeping the bulk phase in a digester in suspension and in full contact with the bacterial population (Metcalf and Eddy 2003). Mixing is therefore critical to avoid the creation of dead zones and a corresponding reduction of the active volume of the digester (short-circuiting of sludge). Pagilla et al. (1997) studied foaming in a gas-mixed and a mechanically-mixed digester receiving the same feed and operated under similar conditions (loading, temperature etc.) and stated that the gas-mixed digester accumulated more foam than the mechanically-mixed digester. It is believed that gas mixing provides favorable conditions for foam generation due to the presence of bubbles in the bulk phase that promote attachment of the surface active and hydrophobic compounds found in sludge onto the bubbles. As the bubbles rise to the surface of the liquid in digesters, the surface active and hydrophobic compounds form a liquid film around the bubbles that prohibits the bubbles from bursting, increases the surface activity and results in higher foaming potential. Barber (2005) also identifies gas mixing systems as an operational cause of $A D$ foaming while Moen (2003) reports that fine bubble gas mixing systems are considered as a cause of foaming for AD.

Apart from the effect of the type of mixing on foaming, poor and excessive mixing have also been suggested as foaming causes (Pagilla et al. 1997, Brown 2002, Moen 2003). However, due to lack of supporting information, it can only be assumed that poor mixing in a full scale anaerobic digester would result in solid / liquid phase separation, accumulation of surface active substances due 
to poor degradation at the air / liquid interface resulting in increased surface activity and potentially foaming. On the other hand, excessive mixing increases the amount of bubbles in the bulk phase enhancing the attachment of surface active and hydrophobic compounds, increasing the surface activity and potentially inducing foaming either in the form of excessive gas mixing or by formation of gas bubbles when the total dissolved gas pressure exceeds the local solution pressure as a result of excessive mechanical mixing (Scardina and Edwards 2006).

In addition, several advantages and disadvantages have been identified between different digester shapes, according to the literature. Cylindrical digesters have a greater surface area compared to egg-shaped digesters allowing larger volumes of gas to be stored and facilitating the accumulation of scum and foam. On the other hand, egg-shaped digesters have a very limited surface area above the bulk phase of the digester reducing the scum and foam accumulation potential. Poor mixing and grit accumulation has been observed in cylindrical digesters creating dead spaces and short circuit of sludge whereas for egg-shaped digesters this is claimed to be reduced. Clearly, cylindrical digesters are more commonly used due to the cost implications of egg-shaped digesters but no information so far has suggested that egg-shaped digesters can prevent foaming occurrence (Metcalf and Eddy 2003).

In summary, mixing along with digester shape play an important role in anaerobic digestion efficiency. There is evidence suggesting that gas mixing 
and excessive mixing contribute to foaming but there will have to be critical concentrations of surface active material in a digester that would attach to the gas bubbles, prolong the bubbles life and hence result in foaming. On the other hand, failure to maintain sufficient mixing during digestion results in stratification and short-circuiting of sludge potentially affecting the microbial activity due to substrate availability. Under these conditions surface active agents and other non-degraded hydrophobic material could rise to the surface of the bulk phase in a digester and potentially induce foaming. It is crucial, therefore, to monitor the mixing efficiency in full scale digesters and investigate any relation of foaming occurrence to inadequate mixing.

\section{Discussion}

$A D$ foaming is currently a recognized operational problem with severe impacts on the performance of STWs. Part of the current paper reviewed knowledge on AS foaming in order to apply the current understanding of an extensively studied area to $A D$ foaming and potentially recognize a relationship between foaming in AS and foaming in AD. According to the literature, the onset of foaming in AS plants has been related to increased surfactant and biosurfactant concentrations. However, their critical concentrations for foam initiation have not been identified due to the numerous compounds involved and the variability between different sludges. Nonetheless, foam stabilization has been attributed to the presence of mycolic acid-containing actinomycetes and the filamentous Microthrix parvicella. Detailed information on the exact foaming mechanisms in 
AS has not been found due to the complexity of the process. Yet, according to Davenport and Curtis (2002), foaming in AS plants is regarded as a 3-phase system comprising of gas bubbles, liquid (wastewater containing surface active agents responsible for foam initiation) and solid particles (hydrophobic bacteria responsible for foam stabilization).

A detailed investigation of the operational parameters of $A D$ including gas mixing, temperature fluctuations, organic loading, and digester shape and their relationship to foaming indicated that these parameters could potentially create favorable conditions for foam initiation in anaerobic digesters. It is therefore important to ensure that operation of anaerobic digesters is not going to facilitate foam generation. Parameters that can be controlled by operators on a daily basis can involve minimizing temperature fluctuations that could lead to poor digestion and potential accumulation of surface active compounds, either as by-products of digestion or as found in the feed sludge. Ensuring sufficient but not excessive mixing by maintaining digesters regularly and preventing grit accumulation and dead spaces is another preventative measure against stratification and hence poor digestion and foaming. Also, overloading and fluctuation of digesters loading should be avoided by daily and weekly monitoring of solids loading rates and the digesters performance. Although the typical ranges of organic loading rates for $A D$, as reported in the literature, are quite broad, it is believed that there is a critical threshold of organic loading that can vary between digesters depending largely on both feed and digested sludge characteristics, beyond which foaming can occur. All the above, however, are at 
this stage suggestions of how foaming can be prevented / minimized in anaerobic digesters as this paper has shown that there is lack of experimental evidence and important gaps in knowledge in order to fully understand how foaming can occur from digester operation, i.e. what the temperature fluctuation needed to induce foaming in $A D$ is, how solids loading and at what concentrations can have an impact on foaming, how the mixing intensity can be assessed in anaerobic digesters.

The effect of surface active agents on foaming is currently poorly supported by experimental data or is site specific and does not represent a systematic investigation of the overall AD foaming problem. This however, could be attributed to the large number of compounds involved and the complexity of the digestion process in terms of continuous degradation and operational temperatures that can have an impact on the physicochemical characteristics of compounds. It is evident however, that the same species of bacteria, Gordonia and Microthrix, have been identified as the foaming causes in both AS and AD. This indicates that there is potentially a relationship between the two processes and $A D$ foaming could be a result of AS foaming due to the high numbers of filamentous and mycolic-acid containing bacteria in SAS carried through to the digesters. By reducing therefore, the numbers of filamentous and other mycolicacid containing bacteria in AS plants the risk of $A D$ foaming could be minimized. However, the above suggestions are not yet supported by experimental evidence in the literature and further research is necessary in order to clearly demonstrate a relationship between AS and AD foaming. Taking into account 
that wastewater foams are 3-phase systems with gas-liquid-solid interactions, it becomes apparent that foaming occurs when the threshold of surface active agents in an anaerobic digester is exceeded and the solids (hydrophobic bacteria) act as stabilizing agents. The determination of the critical concentrations of surface active agents for foam initiation and the critical concentrations of solids for foam stabilization is crucial and monitoring of such parameters could provide a preventative and cost-effective foam control method for the water industry.

\section{Conclusion}

Foaming is a widespread phenomenon in AD. It causes significant operational problems and reduces revenues due to impaired gas recovery. The literature associates foaming incidents with certain design and operational factors and several plausible causal mechanisms have been proposed. There is, however, a lack of experimental evidence to support these. This paper adopted the novel approach of using existing knowledge of activated sludge foaming to provide a conceptual basis for understanding foaming in AD. Wastewater foams are 3phase systems comprising of gas bubbles, liquid and solid particles. This 3phase matrix requires the presence of foam initiating and stabilizing substances. Whilst the literature confirms the presence of candidate foam initiating and stabilizing substances in AD systems their critical concentrations are not yet known.. 


\section{REFERENCES}

Aparicio, I., Santos, J.L., Alonso, E. 2009. Limitation of the concentration of organic pollutants in sewage sludge for agricultural purposes: A case study in South Span. Waste Management 29, 1747-1753

Barber, W.P., 2005. Anaerobic digester foaming: causes and solutions. Water 21, 45-49, IWA [Accessed at http://www-

uk1.csa.com/ids70/results.php?SID=4009hnkld4c223a8Ir72q3vbb1\&id=2, $11 / 06 / 08]$

Barjenbruch, M., Hoffmann, H., Kopplow, O., Tränckner, J., 2000. Minimizing of foaming in digesters by pre-treatment of the surplus-sludge. Water Science and Technology 42, 9, 235-241

Bolzonella, D., Pavan, P., Battistoni, P., Cecchi, F., 2005. Mesophilic anaerobic digestion of waste activated sludge: influence of the solid retention time in the wastewater treatment process. Process Biochemistry 40, 1453-1460

Braguglia, C.M., Minnini, G., Gianico, A., 2007.CNR - Istituto di Ricerca Sulle Acque, Via Reno 1-00198 Rome, Italy [Internet source: http://www.cepis.opsoms.org/bvsaar/cdlodos/pdf/issonicationeffective699.pdf, accessed 12th March 2008]

Brown, S., 2002. Operating a high-rate digester: The Southern Water experience. Water and Environment .CIWEM Journal 16, 116 - 120 
Carr, E.L., Eales, K.L., Seviour, R.J., 2006. Substrate uptake by Gordonia amarae in activated sludge foams by FISH-MAR. Water Science and Technology 54, 1, 39-45

Cartmell, E., Chinaglia, F. 2009. Digester foaming assessment at Southern Water. Commercial report.

Chae K.J., Jang A., Yim S.K., Kim I.S., 2008. The effects of digestion temperature and temperature shock on the biogas yields from the mesophilic anaerobic digestion of swine manure. Bioresource Technology 99, 1 - 6

Clarkson J.R., Cui J.F., Darton R.C., 1999. Protein denaturation in foam. Journal of Colloid and Interface Science 215, $333-338$

De los Reyes, F.L. and Raskin, L., 2002. Role of filamentous microorganisms in activated sludge foaming: relationship of mycolata levels to foaming initiation and stability. Water Research 36, 445-459

Davenport, R.J. and Curtis, T.P., 2002. Are filamentous mycolata important in foaming? Water Science and Technology 46, 1-2, 529-533

Dictionary of the English Language (The American Heritage), 2000. 4th Edition, Houghton Mifflin Company

Dohanyos, M., Zabranska, J., Kutil, J., Jenicek, P., 2004. Improvement of anaerobic digestion of sludge. Water Science and Technology 49, 10, 89-96

Eikelboom, D.H., 2000. Process control of activated sludge plants by microscopic investigation. IWA, London, UK 
Eisner M.D., Jeelani S.A.K., Bernhard L., Windhab E.J., 2007. Stability of foams containing proteins, fat particles and nonionic surfactants. Chemical Engineering Science 62, $1974-1987$

Elmitwalli, T.A., Soellner, J., De Keizer, A., Bruning, H., Zeeman, G., Lettinga, G., 2001. Biodegradability and change of physical characteristics of particles during anaerobic digestion of domestic sewage. Water Research 35, 5, 1311 1317

Foegeding, E.A., Luck, P.J., Davis, J.P., 2006. Factors determining the physical properties of protein foams. Food Hydrocolloids 20, 284-292

Garcia, M.T., Campos, E., Sánchez-Leal, J., Ribosa, I., (2006). Effect of linear alkylbenzene sulphonates (LAS) on the anaerobic digestion of sewage sludge. Water Research 40, 2958-2964

Gerardi, M.H., 2003. The microbiology of anaerobic digesters. Wastewater Microbiology Series, Willey - Interscience, New Jersey, US

Glaser L.A., Paulson A.T., Speers R.A., Yada R.Y., Rousseau D., 2007. Foaming behavior of mixed bovine serum albumin-protamine systems. Food Hydrocolloids 21, $495-506$

Glinski J., Chavepeyer G., Platten J.K., 2000. Surface properties of aqueous solutions of L-leucine. Biophysical Chemistry 84, $99-103$

Gomez-Rico, M.F., Font, i., Aracil, A., Fullana, A., 2007. Analysis of organic pollutants in sewage sludges from the Valencian Community (Spain). Archives of Environmental Contamination and Toxicology 52, 306-316 
Gonzales M., Assadi M., Ouki S., 2003. Effect of sludge composition on the degree of stabilisation and gas production during Mesophilic Anaerobic Digestion (MAD), The $8^{\text {th }}$ European Biosolids and Organic Residuals Conference, Wakefield, UK Handbooks of UK Wastewater Practice: Sewage Sludge Stabilization and Disinfection, 1996. CIWEM, London, UK, ISBN 1870752244

Harrison, D., Cumiskey, A., Le, M.S., Mayhew. M., and Assadi, M., 2004. Advanced Digestion in the UK - Technology Developments and Options for Optimisation of Sludge Assets. Proceedings of WEFTEC 2004 77th Annual Technical Exhibition and Conference, New Orleans, October 2 - 6, 2004. Heard, J., Harvey, E., Johnson, B.B., Wells, J.D., Angove, M.J., 2008. The effect of filamentous bacteria on foam production and stability. Colloids and Surfaces B: Biointerfaces 63, 21-26

Hernandez, M. and Jenkins, D., 1994. The fate of Nocardia in anaerobic digestion. Water Environment Research 66, 828-833

Hwang Y. and Tanaka T., 1998. Control of Microthrix parvicella foaming in activated sludge. Water Research 32 5, 1678 - 1686

Hug, T., 2006. Characterisation and controlling of foam and scum in activated sludge systems. Swiss Federal Institute of Technology Zurich Jensen, J., 1999. Fate and effect of linear alkylbenzene sulphonates (LAS) in the terrestrial environment. The Science of the Total Environment 226, 93-111 
Jensen, J., Jepsen, S.E., 2005. The production, use and quality of sewage sludge in Denmark. Waste Management 25, 239-247.

Kalyuzhnyi, S., Estrada de los Santos, L., Rodriguez Martinez, J., 1998. Anaerobic treatment of raw and preclarified potato-maize wastewaters in a UASB reactor. Bioresource Technology 66, 3, $195-199$

Khan, A.R. and Forster, C.F., 1990. Activated sludge foams: An examination into their stability and their control. Environmental Technology 11, 1153-1159 Kosaric, N., 1992. Biosurfactants in industry. Pure and Applied Chemistry 64, $11,1731-1737$

Kragelund, C., Remesova, Z., Nielsen, J.L., Thomsen, T.R., Eales, K., Seviour, R., Wanner, J., Nielsen, P.H., 2007. Ecophysiology of mycolic acid containing Actinobacteria (Mycolata) in activated sludge foams. FEMS Microbiology Ecology $61,174-184$

Lamelot, M., 2004. Investigation of the causes of foaming in anaerobic sludge digesters. MSc Thesis, School of Water Sciences, Cranfield University, UK Leitao, R.C., van Haandel, A.C., Zeeman, G., Lettinga, G., 2006. The effects of operational and environmental variations on anaerobic wastewater treatment systems: A review. Bioresource Technology 97, 1105-1118

Mamais, D., Andreadakis, A., Noutsopoulos, C., Kalergis, C., 1998. Causes of, and control strategies for, Microthrix parvicella bulking and foaming in nutrient removal activated sludge systems. Water Science and Technology 37, 4-5, 9-17 
Metcalf and Eddy Inc., 2003. Wastewater Engineering, Treatment, Disposal and Reuse, McGraw - Hill, New York, USA, 4th Edition

Moen, G., 2003. Anaerobic digester foaming: Causes and Solutions. Water Environment and Technology 15(8), 70-73

Nino, M.R.R. and Patino, J.M.R., 1998. Surface tension of bovine serum albumin and Tween 20 at the air - aqueous interface. JAOCS 75, 10, 1241 1248

Nitschke, M. and Pastore, G.M., 2006. Production and properties of a surfactant obtained from Bacillus subtilis grown on cassava wastewater. Bioresource Technology 97, 336-341

Oerther, D.B., De Los Reyes, F.L., De Los Reyes, M.F., Raskin, L., 2001. Quantifying filamentous microorganisms in activated sludge before, during and after an incident of foaming by oligonucleotide probe hybridizations and antibody staining. Water Research 35, 14, 3325-3336

Pagilla, K.R., Craney, K.C., Kido, W.H., 1997. Causes and effects of foaming in anaerobic sludge digesters. Water Science and Technology 36, 6-7, 463-470 Petrovic, M. and Barcelo, D., 2004. Analysis and fate of surfactants in sludge and sludge amended soils. Trends in Analytical Chemistry 23, 10-11, 762-771

Pirog, T.P., Shevchuk, T.A., Voloshina, I.N., Karpenko, E.V., 2004. Production of surfactants by Rhodococcus erythropolis Strain EK-1, grown on hydrophilic and hydrophobic substrates. Applied Biochemistry and Microbiology 40, 5, 470475 
Prats, D., Ruiz, F., Vazquez, B., Rodriguez-Pastor, M., 1997. Removal of anionic and nonionic surfactants in a wastewater treatment plant with anaerobic digestion, a comparative study. Water Research 31, 8, 1925-1930

Ron E.Z. and Rosenberg E., 2002. Biosurfactants and oil bioremediation. Current Opinion in Biotechnology 13, 249 - 252

Ross, R.D. and Ellis, L.M., 1992. Laboratory - scale investigation of foaming in anaerobic digesters. Water Environment Research 64, 2, 154-162

Rouimi, S., Schorsch, C., Valentini, C., Vaslin, S., 2005. Foam stability and interfacial properties of milk - protein surfactant systems. Food Hydrocolloids $19,467-478$

Scardina, P. and Edwards, M., 2006. Fundamentals of Bubble Formation during Coagulation and Sedimentation Processes. Journal of Environmental Engineering 132, 6, $575-585$

Schramm L.L., 2000. Surfactants: Fundamentals and applications in the petroleum industry. Cambridge University Press, Cambridge, UK

Soddell, J.A. and Seviour, R.J., 1995. Relationship between temperature and growth of organisms causing Nocardia foams in activated sludge plants. Water Research 29, 6, $1555-1558$

Stainsby, F.M., Soddell, J., Seviour, R., Upton, J., Goodfellow, M., 2002.

Dispelling the 'Nocardia amarae' myth: a phylogenetic and phenotypic study of mycolic-acid containing actinomycetes isolated from activated sludge foam. Water Science and Technology 46, 1-2, 81-90 
Staton, K.L., Alleman, J.E., Pressley, R.L., Eloff J., 2001. 2nd Generation Autothermal Thermophilic Aerobic Digestion: Conceptual Issues and Process Advancements. Joint Residuals and Biosolids Management Conference Biosolids 2001: "Building Public Support", Water Environment Federation Torregrossa, M., Viviani, G., Vinci, V., 2005. Foaming estimation tests in activated sludge systems. Acta hydrochimica et hydrobiologica 33, 3, 240-246 Vardar-Sukan, F., 1998. Foaming: Consequences, Prevention and Destruction. Biotechnology Advances 16, 5-6, 913-948

Varley, J., Brown, A.K., Boyd, J.W.R., Dodd, P.W., Gallagher, S., 2004. Dynamic mulpti-point measurement of foam behaviour for a continuous fermentation over a range of key process variables. Biochemical Engineering Journal 20, 61-72

Verma, S., Bhargava, R., Pruthi, V., 2006. Oily sludge degradation by bacteria from Ankleshwar, India. International Biodeterioration and Biodegradation 57, 207-213

Water Pollution Control Federation ,1996, Operation of municipal wastewater treatment plants. Volume 3. 5th edition. Alexandria, Virginia: Water Environment Federation.

Westlund, A.D., Hagland, E., Rothman, M., 1998. Operational aspects on foaming in digesters caused by Microthrix Parvicella. Water Science and Technology 38, 8-9, 29-34 
Ying G.G., 2006. Fate, behaviour and effects of surfactants and their degradation products in the environment. Environment International 32, 417 431

Zupančič, G.D., Uranjek-Ževart, N., Roš, M., 2008. Full-scale anaerobic codigestion of organic waste and municipal sludge. Biomass and Bioenergy 32, $162-167$. 